\title{
Formamide as the main building block in the origin of nucleic acids Giovanna Costanzo ${ }^{1}$, Raffaele Saladino ${ }^{1,2}$, Claudia Crestini ${ }^{3}$, Fabiana Ciciriello ${ }^{4}$ and Ernesto Di Mauro*5
}

\begin{abstract}
Address: ${ }^{1}$ Istituto di Biologia e Patologia Molecolari, CNR, P.le Aldo Moro, 5, Rome 00185, Italy, ${ }^{2}$ Dipartimento A.B.A.C., Università della Tuscia, Via San Camillo De Lellis, Viterbo, Italy, ${ }^{3}$ Marine Dipartimento di Scienze e Tecnologie Chimiche, Università "Tor Vergata", Rome 00133, Italy, ${ }^{4}$ Fondazione "Istituto Pasteur-Fondazione Cenci-Bolognetti" c/o Dipartimento di Genetica e Biologia Molecolare, Università "La Sapienza" di Roma, P.le Aldo Moro, 5, Rome 00185, Italy and "5rnesto Di Mauro, Dipartimento di Genetica e Biologia Molecolare, Università "La Sapienza" di Roma, P.le Aldo Moro, 5, 00185 Rome, Italy

Email: Giovanna Costanzo - giovanna.costanzo@uniroma1.it; Raffaele Saladino - saladino@unitus.it; Claudia Crestini - crestini@uniroma2.it; Fabiana Ciciriello - fabiana.ciciriello@uniroma1.it; Ernesto Di Mauro* - ernesto.dimauro@uniroma1.it

* Corresponding author
\end{abstract}

from Second Congress of Italian Evolutionary Biologists (First Congress of the Italian Society for Evolutionary Biology) Florence, Italy. 4-7 September 2006

Published: 16 August 2007

BMC Evolutionary Biology 2007, 7(Suppl 2):SI doi:I0.II86/147|-2|48-7-S2-SI

This article is available from: http://www.biomedcentral.com/I47I-2| 48/7/S2/SI

(c) 2007 Costanzo et al; licensee BioMed Central Ltd.

This is an open access article distributed under the terms of the Creative Commons Attribution License (http://creativecommons.org/licenses/by/2.0), which permits unrestricted use, distribution, and reproduction in any medium, provided the original work is properly cited.

\begin{abstract}
The simplest molecules grouping the four most common elements of the universe $\mathrm{H}, \mathrm{C}, \mathrm{O}$ and $\mathrm{N}$ (with the exception of the biologically inert $\mathrm{He}$ ) are isocyanate $\mathrm{HNCO}$ and formamide $\mathrm{H}_{2} \mathrm{NCOH}$. Reasons for the availability of formamide on prebiotic Earth are presented. We review evidence showing that formamide in the presence of largely available catalysts and by moderate heating yields the complete set of nucleic bases necessary for the formation of nucleic acids. Formamide also favours the formation of acyclonucleosides and the phosphorylation and trans-phosphorylation of nucleosides, thus providing a plausible chemical frame for the passage from a simple one-carbon compound to nucleic polymers. Physico-chemical conditions exist in which formamide favours the stability of the phosphoester bonds in nucleic polymers relative to that of the same bonds in monomers. Starting from a formamide-laden environment subject only to the laws of chemistry, a hypothesis is outlined sketching the passage towards an aqueous world in which Darwinian rules apply.
\end{abstract}

\section{Background}

Life is a sturdy phenomenon and its initial steps bona fide originated from robust chemical frames based on firm thermodynamic ground. These assumptions on the simplicity and the necessity of the pre-biogenic processes are mitigated by the consideration that the genetic mechanisms onto which relies life-as-we-know-it today are combinatorially elaborated. In passing from the initial self- organization of chemical information to the potentially infinite complexity of interplaying genotypes and phenotypes that we experience today, evolution did necessarily play the key role.

We have focused on two aspects of the problem: the definition of a plausible chemical frame into which the first spontaneous syntheses could have taken place; the evolu- 
tionarily relevant selective properties and constrains that the first informational polymers had to deal with. The two aspects are intimately connected.

\section{Results}

\section{Is formamide a plausible prebiotic precursor?}

The nature of the chemicals that played the role of prebiotic precursors on primitive Earth is still a debated argument. In a general approach to the problem, the following physical and chemical properties of the simple organic compounds under consideration should be taken into account. Namely: (i) the relative abundance of the starting biogenic materials, to be considered a pre-requisite for the early onset [1-4] of genetic processes on this planet; (ii) their stability; (iii) their ability to react to give more complex structures following reproducible pathways. The formation of precursors based on simple chemical processes, and the quasi-simultaneous presence of all the building blocks to be used for the assembling of informational molecules, are other important requisites.

\section{(i) Availability}

Formamide $\left(\mathrm{H}_{2} \mathrm{NCOH}\right)$ meets the required criteria of abundance and diffusion in the Universe. The analysis of the molecular composition of comets-asteroids and of the interstellar clouds shows that the compounds made of the 4 more common and biologically relevant elements $\mathrm{H}, \mathrm{O}$, $\mathrm{C}$ and $\mathrm{N}$ (excluding $\mathrm{He}$ ) are isocyanate HNCO and formamide $\mathrm{H}_{2} \mathrm{NCOH}$ [5]. Formamide was detected in the gas phase of interstellar medium [6], in the long period comet Hale-Bopp [7], and tentatively in the solid phase of grains around the young stellar object W33A [8]. Possible formamide production under Europa-like conditions was observed (Hand, K.; Carlson, R. W., Department of Geological \& Environmental Sciences, Stanford University; personal communication, July 2006).

\section{(ii) Stability}

Formamide meets the required criteria of stability. This topic must be considered in connection with hydrogen cyanide (HCN) chemistry. Since the pivotal experiment by Orò [9] on the synthesis of adenine from HCN, numerous studies were devoted to assess the role of this compound in the origin of primordial nucleic acids [10]. Nevertheless, two problems remain unsolved in the prebiotic relevance of HCN chemistry: (i) the thermodynamic instability of HCN under hydrolytic conditions, (ii) the narrow panel of nucleobases, limited only to purines that can be formed by its condensation process. In the perspective of this latter observation, an all-purine precursor of nucleic acids was proposed, in which the pyrimidines present in extant nucleic acids would be post-enzymatic substitutes for their isoelectronic and isogeometric purines [11]. HCN is a gas under a wide range of environmental conditions. Thus, HCN chemistry in homogene- ous solution (the largely accepted chemical prebiotic scenario on the primitive Earth) firstly requires absorption in water. After the adsorption process polymerization and hydrolysis of HCN compete, the results being determined by its concentration. The two reactions are equivalent at concentrations of HCN between 0.01 and $0.1 \mathrm{M}$ (between pH 8 and 9). Hydrolysis to formamide (Figure 1, equation A) predominates in dilute solutions while polymerization takes over at higher concentrations [12]. The steady state concentration of $\mathrm{HCN}$ in the primitive ocean was calculated, on the basis of the estimated rates of its production and hydrolysis, to be at pH7 $4 \times 10^{-12} \mathrm{M}$ at $100^{\circ} \mathrm{C}$ and $2 \times$ $10^{-5} \mathrm{M}$ at $\mathrm{O}^{\circ} \mathrm{C}$. These concentrations are far too low for polymerization to nucleobases to occur, thus favouring hydrolysis to formamide $[13,14]$.

Since HCN is more volatile than water it cannot be concentrated by simple evaporation at $\mathrm{pH}$ lower than its $\mathrm{pKa}$ $\left(9.2\right.$ at $\left.25^{\circ} \mathrm{C}\right)[15]$. This suggested eutectic freezing as a means for HCN to reach the sufficient concentration for polymerization [16].

In the same study, the hydrolysis rate (and the steady state concentration) of formamide to ammonium formate (Figure 1, equation $\mathrm{B}$ ) was also estimated as $2 \times 10^{-18}, 1 \times$ $10^{-15}$ and $1 \times 10^{-9} \mathrm{M}$, at 200,100 and $0^{\circ} \mathrm{C}$ respectively, assuming that in the primitive ocean formamide was formed only by HCN hydrolysis.

On the basis of these data the authors suggest that "it is unlikely that formamide could have served a significant role in the prebiotic chemistry", a quite definitive sentence for this compound!

However, this assumption does not take into consideration that (i) formamide can be formed from prebiotic compounds largely diffused on the primitive Earth other

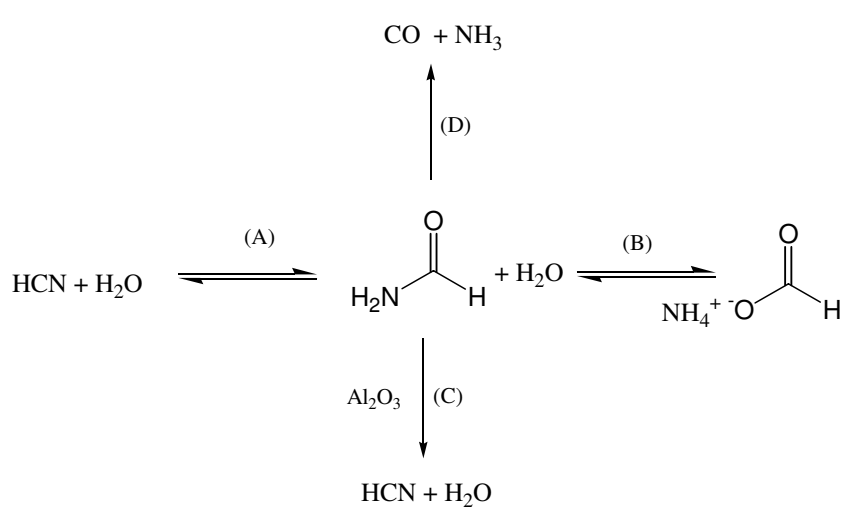

\section{Figure I}

The basic formamide chemistry. A scheme summarizing basic formamide chemistry; more details in text. 
than $\mathrm{HCN}$, and (ii) that formamide is liquid under a wide range of temperature and pressure values, with a boiling point of $210^{\circ} \mathrm{C}$ and very limited azeotropic effects [17]. Thus, unlike HCN, formamide in a drying lagoon model can be easily concentrated, increasing its stability upon concentration and providing the adequate concentration for polymerization to nucleobases to occur. The hydrolysis of formamide in water was revisited by studying the solvent deuterium kinetic isotope effect. This analysis provided a value of the constant $\mathrm{k}_{\mathrm{hyd}}$ of $1.1 \times 10^{-10} \mathrm{~s}^{-1}$, corresponding to a $\mathrm{t}_{1 / 2}$ of ca. $200 \mathrm{yr}$ at $25^{\circ} \mathrm{C}$ and $\mathrm{pH} 7.0$ [18].

\section{(iii) Reactivity}

As an organic compound able to generate "in situ" many other simple chemicals useful for the synthesis of nucleobases, formamide can be considered as a multifunctional prebiotic precursor. The ratio of the afforded precursors depends on the specific environmental conditions.

At $190-210^{\circ} \mathrm{C}$ under atmospheric pressure formamide thermally decomposes either to ammonia $\left(\mathrm{NH}_{3}\right)$ and carbon monoxide (CO) (Figure 1, equation $\mathrm{C}$ ) or to $\mathrm{HCN}$ and water (Figure 1, equation D). The formation of HCN is usually favoured in the presence of suitable catalysts, i.e., with aluminium oxides the yield at temperatures between $400^{\circ} \mathrm{C}$ and $600{ }^{\circ} \mathrm{C}$ is $>90 \%$, while in the absence of catalysts the reaction forming $\mathrm{NH}_{3}$ and $\mathrm{CO}$ predominates [19]. Further decomposition products are also detected. These include polymeric hydrogen cyanide derivatives $[20]$ potentially producing nucleobases under hydrolytic conditions. Due to its high dielectric constant [21] formamide is in addition an excellent solvent for both metal oxides and inorganic salts, which can act as catalysts during the condensation processes to nucleobases.

Thus, the composition of a reaction mixture based on formamide as the main component is tuned by the composition of the environmental reactor providing, at difference from HCN, all the prebiotic precursors necessary for the synthesis of both purine and pyrimidine nucleobases. The composition of the panel of the prevailing products depends on the specific physical and chemical properties of the catalysts present in the reaction medium, as detailed below.

\section{The synthesis of nucleic precursors from formamide}

Nucleic bases, one amino acid and a condensing agent

Nucleic bases

We have observed that formamide has the unique property of condensing into both purine and pyrimidine nucleobases simply upon heating at $110-160^{\circ} \mathrm{C}$ in the presence of largely diffused metal oxides and minerals [22-26]. The products obtained are listed in Table 1, crossed with the catalysts tested and grouped as a function of (approximate) increasing complexity. Purine is the only compound obtained by heating formamide in the absence of catalysts. The most relevant aspects of this large ensemble of products are:

- the panel of compounds obtained in the presence of each catalyst is 'clean'. Only few products are observed, in certain cases the synthesis being highly specific, as in the case of the phosphate mineral pyromorphite yielding exclusively cytosine or in the case of childrenite yielding almost only $\mathrm{N}$-formylglycine. In other instances richer panels of products are obtained, as with pyrophosphate $\mathrm{Na}_{4} \mathrm{P}_{2} \mathrm{O}_{7}$ yielding (in addition to purine) adenine, hypoxantine (a bioisoster of guanine), uracil, cytosine, $\mathrm{N}$ formylglycine and carbodiimide; and with $\mathrm{TiO}_{2}$ yielding (in addition to purine) adenine, $\mathrm{N}^{9}$-formylpurine, $\mathrm{N}^{9}-\mathrm{N}^{6}-$ diformyladenine, cytosine, thymine and 5-hydroxymethyluracil.

- Quite interestingly $\mathrm{TiO}_{2}$ also catalyzes the synthesis of purine acyclonucleosides (not reported in Table 1, see Ref 23). This observation is of particular prebiotic relevance because of the known difficulty of building under prebiotic conditions the $\beta$-glycosidic bond between separately synthesized nucleobases and sugars [27]. Anyhow, even in the instance of relatively higher complexity mixtures the products profiles keep their character of neatness and do not usually contain degradation products nor additional classes of compounds.

\section{Glycine and carbodiimide}

The $\alpha$-amino acid derivative $N$-formylglycine was detected in formamide-based syntheses catalyzed by phosphate-minerals, often accompanied by carbodiimide [26]. The synthesis of carbodiimide, which is an important agent for the condensation of aminoacids into peptides, could be responsible for the formation of formylglycine from in situ generated glycine [26], suggesting a role for the formamide-phosphate system in the prebiotic synthesis of peptides.

Intermediates of the synthetic pathways for components of extant nucleic acids are also observed, i.e., 4-aminoimidazole-5-carboxamide (AICA), 4-formylaminoimidazole-5-carboxamide (f-AICA) and 5-hydroxymethyluracil.

The chemical mechanisms onto which all these syntheses are based are described and critically discussed in [28-30].

\section{The chemomimesis concept as a selector of prebiotic precursors}

As mentioned above, the identity of the first prebiotic precursors of nucleic acids is still an argument of debate. On the other hand, the analysis of the mechanism of reaction of simple organic molecules reveals instances in which 
Table I: Catalysed synthesis of nucleic acid components and precursors from formamide

\begin{tabular}{|c|c|c|c|c|c|c|c|c|c|c|c|c|c|c|c|c|c|c|}
\hline \multirow[b]{2}{*}{ Catalyst|Product } & \multirow[b]{2}{*}{ I } & \multirow[b]{2}{*}{2} & \multirow[b]{2}{*}{3} & \multirow[b]{2}{*}{4} & \multicolumn{6}{|c|}{ Pyrimidines } & \multicolumn{3}{|c|}{ Imidazoles } & \multicolumn{5}{|c|}{ Purines } \\
\hline & & & & & 5 & 6 & 7 & 8 & 9 & 10 & II & 12 & 13 & 14 & 15 & 16 & 17 & 18 \\
\hline Silica & - & - & - & + & - & - & - & - & + & - & - & - & - & + & - & + & - & - \\
\hline Alumina & - & - & - & + & - & - & - & - & + & - & - & - & - & +++++ & - & + & - & - \\
\hline Kaolin & - & - & - & + & - & - & - & - & - & - & - & - & - & +++++ & - & - & - & - \\
\hline Zeolite & - & - & - & + & - & - & - & - & + & - & - & - & - & +++++ & - & + & - & - \\
\hline $\mathrm{CaCO}_{3}$ & - & - & - & - & - & - & - & - & - & - & - & - & - & +++++ & - & - & - & - \\
\hline KP-IO Clay ${ }^{a}$ & - & - & - & - & - & + & - & - & +++ & - & - & - & ++ & ++++ & +++ & ++ & - & + \\
\hline K-30 Claya & - & - & - & - & - & + & - & - & +++ & - & - & - & ++++ & + & ++++ & ++++ & - & - \\
\hline KSF Claya & - & - & - & - & - & + & - & - & +++ & - & - & ++++ & +++ & ++++ & + & +++ & - & + \\
\hline Al-PILC Claya & - & - & - & - & - & + & - & - & +++ & - & - & +++ & + & +++ & + & + & - & + \\
\hline $\mathrm{TiO}_{2}$ & - & - & - & - & - & - & + & - & + & + & - & - & - & +++ & +++ & ++ & + & - \\
\hline $\mathrm{MgFeSiO}_{4}$ & + & - & - & - & ++ & + & - & - & +++ & - & - & - & - & + & - & - & - & - \\
\hline $\mathrm{Mg}_{1.5} \mathrm{Fe}_{0.5} \mathrm{SiO}_{4}$ & + & - & - & - & ++ & - & - & - & ++++ & - & - & - & - & - & - & - & - & - \\
\hline $\mathrm{Mg}_{0.5} \mathrm{Fe}_{1.5} \mathrm{SiO}_{4}$ & - & - & - & - & +++++ & + & - & - & +++ & - & - & - & - & - & - & - & - & - \\
\hline $\mathrm{Fe}_{2} \mathrm{SiO}_{4}$ & + & - & - & - & +++++ & + & - & - & +++++ & - & - & - & - & + & - & - & - & - \\
\hline $\mathrm{Mg}_{2} \mathrm{SiO}_{4}$ & + & - & - & - & - & - & - & - & - & - & - & - & - & + & - & - & - & - \\
\hline $\mathrm{Na}_{3} \mathrm{PO}_{4}$ & + & + & ++ & - & - & + & - & - & ++++ & - & - & - & - & +++ & - & - & - & - \\
\hline $\mathrm{Na}_{4} \mathrm{P}_{2} \mathrm{O}_{7}$ & - & + & + & - & - & + & - & + & +++ & - & - & - & - & ++ & - & + & - & + \\
\hline $\mathrm{Na}_{5} \mathrm{P}_{3} \mathrm{O}_{9}$ & - & + & ++ & - & - & - & - & - & + & - & - & - & - & + & - & - & - & - \\
\hline Turquoise & - & - & + & - & - & - & - & - & ++ & - & - & - & - & ++ & - & - & - & - \\
\hline Childrenite $^{c}$ & + & - & +++++ & - & - & - & - & - & - & - & - & - & - & - & - & - & - & - \\
\hline Ludlamite $^{c}$ & - & - & +++++ & - & - & - & - & - & - & - & - & - & - & + & - & - & - & - \\
\hline Vivianite ${ }^{c}$ & + & - & ++++ & - & - & - & - & - & - & - & - & - & - & + & - & - & - & - \\
\hline Vauxite $^{c}$ & - & - & ++++ & - & - & - & - & - & - & - & - & - & - & + & - & - & - & - \\
\hline Lazulite $^{c}$ & - & - & +++ & - & - & + & - & - & + & - & + & - & - & + & - & - & - & - \\
\hline Hureaulitec & - & + & - & - & - & + & - & - & ++ & - & - & - & - & + & - & - & - & - \\
\hline Augelite $^{c}$ & - & - & +++ & - & - & - & - & - & + & - & - & - & - & + & - & - & - & - \\
\hline Wavellitec & - & - & + & - & - & - & - & - & + & - & - & - & - & + & - & - & - & - \\
\hline Libethenite $^{c}$ & - & + & + & - & - & + & - & - & + & - & - & - & - & - & - & - & - & - \\
\hline Pyromorphitec & - & - & - & - & - & - & - & - & + & - & - & - & - & + & - & - & - & - \\
\hline
\end{tabular}

a: Montmorillonite clays, b: Cosmic Dust Analogues, c: phosphate minerals. Data from [22] for the syntheses catalyzed by silica, alumina, kaolin, zeolites, and $\mathrm{CaCO}_{3}$; from [23] for $\mathrm{TiO}_{2}$; from [24] for clays and from [25] for olivines; from [26] for the soluble and mineral phosphates, as listed; $\mathrm{mg}$ of product per gram of formamide. +: 0.1-5.0 mg; ++: 5-10 mg; +++: $10-20 \mathrm{mg}$; ++++: $20-40 \mathrm{mg} ;+++++:>40 \mathrm{mg}$. Products are: $\mathrm{I}=$ Urea; $2=$ Carbodiimide; 3 = N-Formylglycine; 4 = Hydroxypyrimidine; $5=4(3 \mathrm{H})$-Pyrimidinone; 6 = Uracil; 7 = 5-Hydroxymethyluracil; $8=$ Dihydroxyuracil; 9 = Cytosine; 10 = Thymine; 11 = Parabanic acid; 12 = AICA: 5-Aminoimidazole-4-carboxamide; 13 = fAICA: 5-Formamidoimidazole-4-carboxamide; 14 = Purine; 15 = N9-formylpurine; 16 = Adenine; 17 = N9, N6-Diformyladenine; 18 = Hypoxanthine.

key intermediates are also produced corresponding to those observed in extant biological pathways. The concept of chemomimesis applies to these correspondence. This term, first introduced by Eschenmoser and Loewenthal in 1992 [31], generally refers to a chemical reaction pathway that can be used as a template for the enzymatic processes that will appear later in evolution, yielding the same final products. This property can in principle distinguish two classes of prebiotic precursors: the precursors that are able to generate a chemomimetic process from those that are not. Formamide chemistry shows interesting cases of chemomimesis.

As an example, 5-aminoimidazole-4-carboxamide (AICA) and 5-formamido-imidazole-4-carboxamide (f-AICA), obtained in high yield in addition to hypoxanthine upon heating formamide in the presence of montmorillonites (Table 1), are also key intermediates (as ribonucleotide-
5 '-monophosphates) in the last steps of the extant biosynthesis of inosine-5'-monophosphate (IMP), the main route to purine nucleotides in the cell (Figure 2).

Similarly, the addition of formaldehyde to a preformed uracil scaffold during the synthesis of thymine from formamide and $\mathrm{TiO}_{2}$ is a key step for the introduction of the methyl moiety, in agreement with the extant biosynthesis of thymidine. In this reaction a formaldehyde unit is added to uridine, masked as the activated methylene unit of methylene tetrahydrofolate (MTHF) to give 5hydroxymethyluracil-5'-monophosphate (HMU-5'monophosphate). Thymidine will be obtained by successive hydride shift rearrangement.

The possibility that early chemical events played the role of templates for the development of more complex (but also more efficient and selective) enzymatic pathways is a 


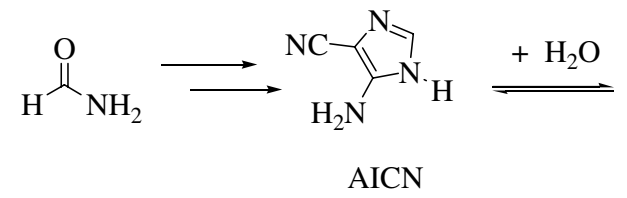<smiles>NC(=O)c1nc[nH]c1N</smiles>

AICA

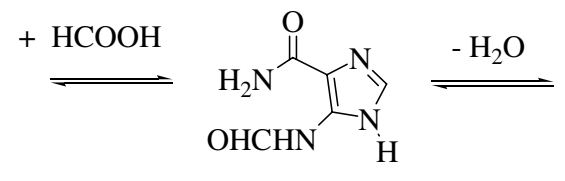

f-AICA

Hypoxanthine

Figure 2

Chemomimesis instances in formamide chemistry. See text for details.

fascinating concept to be further evaluated in the study of the molecular evolution of informational polymers.

\section{Problems in prebiotic polymerization Activated precursors}

Evolution of the genetic information based on linear polymers implies a template-mediated replication mechanism. Templated reproduction allows the accumulated information to be maintained and occasionally modified, thus establishing chemically-based evolutionary rules. Non-enzymatic self-replicating systems based on template-directed synthesis of oligonucleotides were reported (among which those reported in [32-39], reviewed in [30]), providing the proof of principle for the plausibility of this general mechanism. The first pre-genetic polymers were not necessarily made of the sugar moieties that compose extant nucleic acids, nor were the nucleosides forcibly connected by the phosphoester linkages that we experience today. Comprehensive analyses of the possible alternatives were reported $[10,30,40]$. However, in the absence of direct evidences or of solid indications to the contrary, it is safely assumed that genetic evolution originated based on RNA-like polymers, that ribose and phosphodiester bonds were the actual components whose properties allowed and chick-started evolution, that the molecular horses were not changed during the run. The reasons favouring phosphate as a connecting element are well established [41].

A general problem derives from the fact that the formation of a phosphodiester bond is thermodynamically uphill. Thus, the template-directed protein-free prebiotic synthesis of phosphodiester-linked oligonucleotides most probably required the use of chemically activated nucleotides.

\section{Formamide-catalyzed phosphorylation of nucleosides}

The prebiotic relevance of the mechanisms proposed for the production of activated nucleosides is questionable $[10,42]$. The otherwise important observation that drying the chemically activated nucleoside 5'-phosphorimidazolide-adenosine (ImpA) onto the surface of a Montmorillonite clay a pre-absorbed decanucleotide could be elongated by up to 30 additional nucleotides [36,37] and similar results in comparable systems in [38], suffer from the same limitation. Thus, an efficient and robust catalytic mechanism for the activation (possibly phosphorylation) of nucleosides was probably involved. We have observed that phosphorylation of nucleosides readily occurs in the presence of formamide and of a phosphate donor. The donor could be a soluble mono-, di- or triphosphate; or a different phosphorylated nucleoside; or one of several crystalline phosphate minerals among which hydroxylapatite, libethenite and pseudomalachite (data not detailed, submitted for publication elsewhere). Phosphorylation occurred on the $5^{\prime}$, or the $3^{\prime}$, or the $2^{\prime} \mathrm{C}$ atoms of the ribose moiety, and $2^{\prime}: 3^{\prime}$ and $3^{\prime}: 5^{\prime}$ cyclic phosphoester forms were also observed. Based on the ground-breaking observation by Orgel [43] that dinucleoside diphosphates formed from adenosine 2':3' cyclic phosphate, this cyclic phosphate ribonucleotide system is of possible particular prebiotic relevance.

\section{Aqueous versus non-aqueous}

The chemically relatively easy formation of linear polymers from activated precursors does not solve the problem of their origin. The standard-state Gibbs free energy change $\left(\Delta G^{\circ}\right)$ problem, as critically evaluated by van Holde [44], and the intrinsic instability of polymers in solution limit the formation and the survival of polymers in aqueous environments. The $\Delta \mathrm{G}^{\circ}$ problem is the major obstacle for liquid-phase polymerizations in prebiotic conditions.

The phosphorylation of nucleosides on mineral surfaces mentioned above was obtained in the presence of formamide. Thus, activated nucleic monomers can form in a liquid non-aqueous environment in conditions compatible with the thermodynamics of polymerization, providing an operational solution. If formamide afforded activated precursors by phosphorylation of nucleosides and allowed their polymerization by a simple trans-phosphorylation reaction (a still hypothetical but chemically plausible process), the limiting factor for the evolution of pregenetic molecules would become the stability of the resulting polymerized forms. In other words, when considering the conditions in which pre-genetic polymers could spontaneously polymerize, replicate and evolve, the physico-chemical parameters favouring or allowing the survival of the very polymeric state are of paramount relevance. Hence the interest of defining the initial thermody- 
namic niches into which the polymeric state could have been favoured over the monomeric one.

These niches were identified for both the deoxyribo [45] and the ribo [46] systems, showing that defined combinations of temperature and solvent favour the polymeric state. These niches are remarkably broader for RNA than for DNA (cfr data in [45] versus [46]).

In the frame of the "RNA world" hypothesis, this finding shows that in addition to the three important properties of RNA [(i) its capacity to encode and express genetic information; (ii) the variety of structures and hence of functions it assumes; (iii) its catalytic abilities] the property of favoured persistence should also be considered. This fourth property consists of the ensemble of thermodynamic and kinetic parameters pertaining to the polymerization process and polymers stability. The conditions favouring oligomeric persistence could potentially provide information about the environment in which the urgenetic molecules came into existence and survived.

\section{Stability as critical phenotype for the evolution of informational polymers}

In reconstructing the passage from monomers to the information-bearing polymers that we know at present, and summarizing the data reported above, we have observed that formamide 1) condenses into all the nucleic bases necessary to form present-day nucleic acids. This process only requires moderate temperature (110$160^{\circ} \mathrm{C}$ ) and easily available catalysts. 2) Several compounds are formed encasing a hidden $\beta$-glycosidic bond, potentially solving the chemical rebus posed by the nonreactivity of nucleic bases with sugars. 3) Formamidebased phosphorylation of preformed nucleosides was observed (data submitted elsewhere), providing a plausible solution to the problem of the chemically robust mechanism needed for a non-fastidious high-yield production of activated precursors. Polymers formation might be hypothesized through a formamide-driven template-directed trans-phosphorylation process. The suitable template could be provided by a mineral surface or by nucleic polymers. These processes provide a simple-chemistry frame into which all the steps from the one-carbon atom compound $\mathrm{H}_{2} \mathrm{NCOH}$ to activated nucleotides have been described. All these reactions require formamide as building material and/or as catalyst.

However, extant organisms live in water, not in formamide. And the structure and properties of nucleic acids strongly hint that interaction with water is one of their most intimate properties. At what stage could the passage from a formamide environment to water have occurred?
At this point we are on hypothetical grounds. Let us start from a model in which the synthesis of a ribo oligonucleotide has occurred by connecting pre-synthesized nucleosides [22-26, especially ref. [23]], phosphorylated by formamide-catalyzed phosphorylation and joined by formamide catalyzed trans-phosphorylation (hypothetical). Phosphodiester bridges between nucleosides could have occurred between monomers bound as single units on phosphate mineral surfaces providing both a source for phosphate moieties and a correct spatial ordering. The P$P$ distance in a stretched nucleic acid is a well established $9.15 \AA$, in good correspondence with the crystal cell dimensions of phosphate minerals whose $a$ and $b$ values in a large number of different minerals are encompassed between 6 and $10 \AA$ [47] (first generation stage). Alternatively, or at a later stage, phosphodiester bridges would have formed between activated monomers bound as single units on nucleic acid template (second generation stage). Both stages require formamide as the driving chemical for phosphate bridge formation.

\section{Conclusion}

Passage to water from a formamide-based chemically active environment may be conceived only if advantageous under Darwinian selection. We have observed [46] that in water the 3' phosphoester bond in RNA (and, remarkably, much less so in DNA) may be more stable that the corresponding bond in the starting monomers. The structural properties conferring such an advantage (i.e., protection towards hydrolysis induced by base stacking, differential deprotonation rates, different kinetics and/or frequency of the cleavage-inducing in-line configuration made of the attacking 2'-oxygen nucleophile with the 5 -oxyanion leaving group and the target phosphorus center [48], etc.) are currently under investigation. Whatever the structural reasons, the higher stability of the polymeric form is exactly what can be seen as an advantageous proto-phenotype, conferring to a neoformed polymer the ability to maintain the chemical information created by the assembling of dispersed monomers.

In spite of its largely hypothetical character, this model (i) is based on simple state-of-art chemistry, (ii) relies on easily available building material and on common catalysts, (iii) may be brought to experimental verification, and (iv) brings in close proximity a purely chemical world with a system in which properties deriving from combinatorial events become relevant selective attributes. In this overlapping worlds the first parameter for fitness is stability (first: survive). Molecules stable enough to reproduce would thus be granted the possibility to explore evolutionary space. 


\section{Competing interests}

The authors declare that they have no competing interests.

\section{Authors' contributions}

All authors contributed equally to the experiments and models described.

\section{Acknowledgements}

This work was supported by the Italian Space Agency Project MoMa and Centro di Eccellenza di Biologia e Medicina Molecolare, Università "La Sapienza".

This article has been published as part of BMC Evolutionary Biology Volume 7 Supplement 2, 2007: Second Congress of Italian Evolutionary Biologists (First Congress of the Italian Society for Evolutionary Biology). The full contents of the supplement are available online at http://www.biomedcen tral.com//47/-2/48/7? issue $=$ S2

\section{References}

I. Dunlop JSR, Muir MD, Milne VA, Groves DI: A new microfossil assemblage from the Archaean of Western Australia. Nature 1978, 274:676-678

2. Lazcano A, Miller SL: How Long Did It Take for Life to Begin and Evolve to Cyanobacteria? I Mol Evol 1994, 39:546-554

3. Westall F, De Wit MJ, Dann J, Van Der Gaast S, De Ronde C Gerneke D: Early Archaean fossil bacteria and biofilms in hydrothermally-influenced, shallow water sediments, Barberton greenstone belt, South Africa. Precambrian Res 200I, 106:93-116.

4. van Zuilen MA, Lepland A, Arrhenius G: Reassessing the evidence for the earliest traces of life. Nature 2002, 4 I 8:627-630.

5. Millar T]: Organic Molecules in the Interstellar Medium. Astrobiology: Future Perspectives, Kluwer Eds 2004, Chapter 2:17-3I. [and refs therein]

6. Crovisier J: The molecular complexity of comets. Astrobiology: Future Perspectives, Kluwer Eds 2004, Chapter 8:179-203. [and refs therein]

7. Bockelee-Morvan D, Lis DC, Wink JE: Cometary and Interstellar Material. Astron Astrophys 2000, 353:1101-III4.

8. Schutte WA, Boogert ACA, Tielens AGGM, Whittet DCB, Gerakines PA, Chiar JE, Ehrenfreund P, Greenberg JM, Dishoeck van EF, De Graauw Th: Weak Ice Absorption Features at 7.24 and 7.41 : $\mu \mathrm{m}$ in the Spectrum of the Obscured Young Stellar Object W 33A. Astron Astrophys 1999, 343:966-976.

9. Oró J: Synthesis of adenine from ammonium cyanide. Biochim Biophys Res Comm 1960, 2:407-4I2.

10. Orgel LE: Prebiotic chemistry and the origin of the RNA world. Crit Rev Biochem Mol Biol 2004, 39:99-123.

II. Wachtershauser G: All-Purine Precursor of Nucleic Acids. PNAS 1988, 85: II34-II35

12. Sanchez RA, Ferris JP, Orgel LE: Studies in prebiotic synthesis. II. Synthesis of purine precursors and amino acids from aqueous hydrogen cyanide. J Mol Biol 1967, 30:223-253.

13. Stribling R, Miller SL: Energy yields for hydrogen cyanide and formaldehyde syntheses: the $\mathrm{HCN}$ and amino acid concentrations in the primitive ocean. Orig Life Evol Biosp 1987 | 7:26|-273.

14. Miyakawa S, Cleaves HJ, Miller SL: The cold origin of life: A. Implications based on the hydrolytic stabilities of hydrogen cyanide and formamide. Orig Life Evol Biosph 2002, 32:195-208.

15. Shapiro R: Comments on 'concentration by evaporation and the. prebiotic synthesis of cytosine. Orig Life Evol Biosph 2002 32:275-278.

16. Miyakawa S, Cleaves HJ, Miller SL: The cold Origin of Life: B. Implications Based on Pyrimidines and Purines Produced from Frozen Ammonium Cyanide Solutions. Orig Life Evol Biosph 2002, 32:209-218.

17. Formic acid and derivatives (Formamide). In ECT Kirk-Othme Encyclopedia of Chemical Technology Volume II. Wiley Interscience; 1978:258-262.
18. Slebocka-Tilk H, Sauriol F, Monette M, Brown RS: Aspects of the hydrolysis of formamide: revisitation of the water reaction and determination of the solvent deuterium kinetic isotope effect in base. Canadian / Chem 2002, 80: I343-I350.

19. Formic acid and derivatives (Formamide). In ECT Kirk-Othmer Encyclopedia of Chemical Technology Volume II. fourth edition. Wiley Interscience Ed; 1994: I.

20. Elvers B, Hawkins S, Ravenscroft M, Rounsaville JF, Schulz G: UIImann's Encyclopedia of Industrial Chemistry Volume A I2. VCH, Weinheim (Germany); 1989:।.

21. Faebe J, Regitz M, Ed: Römpps Chemie-Lexikon Volume 2. 9th edition. Georg Thieme Verlag; 1990:|425-|426.

22. Saladino R, Crestini C, Costanzo G, Negri R, Di Mauro E: A possible prebiotic synthesis of purine, adenine, cytosine, and $4(3 \mathrm{H})$ pyrimidone from formamide: implications for the origin of life. Bioorg Med Chem 200I, 9: I 249-I253.

23. Saladino R, Ciambecchini U, Crestini C, Costanzo G, Negri R, Di Mauro E: One-pot TiO $\mathrm{T}_{2}$-Catalyzed Synthesis of Nucleic Bases and Acyclonucleosides from Formamide: Implications for the Origin of Life. ChemBioChem 2003, 4:5I4-52I.

24. Saladino R, Crestini C, Ciambecchini U, Ciciriello F, Costanzo G, Di Mauro E: Synthesis and degradation of nucleobases and nucleic acids by formamide in the presence of montmorillonites. ChemBioChem 2004, 5:1558-I566.

25. Saladino R, Crestini C, Neri V, Brucato JR, Colangeli L, Ciciriello F, Di Mauro E, Costanzo G: Synthesis and degradation of nucleic Acid components by formamide and cosmic dust analogues. ChemBioChem 2005, 6:1368-1374.

26. Saladino R, Crestini C, Neri V, Ciciriello F, Costanzo G, Di Mauro E: Origin of informational polymers: The concurrent roles of formamide and phosphates. ChemBioChem 2006, 7:1707-I7|4.

27. Fuller WD, Sanchez RA, Orgel LE: Studies in prebiotic synthesis. VI. Synthesis of purine nucleosides. J Mol Biol 1972, 67:25-33.

28. Saladino R, Crestini C. Costanzo G, Di Mauro E- Advances in the Prebiotic Synthesis of Nucleic Acids bases. Implications for the Origin of Life. Current Organic Chemistry 2004, 8: | 425-I 443.

29. Saladino R, Crestini C, Costanzo G, Di Mauro E: On The Prebiotic Synthesis of Nucleobases, Nucleotides, Oligonucleotides, pre-RNA and pre-DNA Molecules. In Topics In Current Chemistry, "Prebiotic Chemistry" Volume 259. Edited by: Walde P. Springer Verlag; 2005:29-68.

30. Saladino R, Crestini C, Ciciriello F, Costanzo G, Di Mauro E: Formamide Chemistry and the Origin of Informational Polymers. Chemistry \& Biodiversity in press. accepted 2 Nov 2006

31. Eschenmoser A, Loewenthal E: Chemistry of potentially prebiological natural products. Chem Soc Rev 1992, 2 I: I- I6.

32. Orgel LE: Molecular replication. Nature 1992, 358:203-209.

33. Sievers D, von Kiedrowski G: Self-replication of complementary nucleotide-based oligomers. Nature 1994, 369:22 I-224.

34. Li KC, Nicolaou T: Chemical self-replication of palindromic duplex DNA. Nature 1994, 369:218-221.

35. Sulston J, Lohrmann R, Orgel LE, Miles HT: Nonenzymatic synthesis of oligoadenylates on a polyuridylic acid template. PNAS USA 1968, 59:726-733.

36. Joyce GF, Inoue T, Orgel LE: Non-enzymatic template-directed synthesis on RNA random copolymers. $\operatorname{Poly}(C, U)$ templates. J Mol Biol 1984, I 76:279-306.

37. Prabahar KJ, Ferris JP: Adenosine Derivatives as PhosphateActivating Groups for the Regioselective Formation of 3',5'Linked Oligoadenylates on Montmorillonite: Possible Phosphate-Activating Groups for the Prebiotic Synthesis of RNA. J Am Chem Soc 1997, I 1 9:4330-4337.

38. Ferris JP, Hill AR, Liu R, Orgel LE: Synthesis of Long Prebiotic Oligomers on Mineral Surfaces. Nature 1996, 381:59-61.

39. Ertem G, Ferris JP: Synthesis of RNA Oligomers on Heterogeneous Templates. Nature 1996, 379:238-240.

40. Hutter D, Blaettler MO, Benner SA: From Phosphate to Bis(methylene) Sulfone: Non-lonic Backbone Linkers in DNA. Helvetica Chimica Acta 2002, 85:2777-2806.

4I. Westheimer FH: Why nature chose phosphates. Science 1987 235: $1173-1178$

42. Hill AR, Orgel LE, Wu T: The limits of template-directed synthesis with nucleoside-5'-phosphoro(2-methyl)imidazolides. Orig Life Evol Biosph 1993, 23:285-290. 
43. Renz M, Lohrmann R, Orgel LE: Catalysts for the polymerization of adenosine cyclic 2',3'-phosphate on a poly (U) template. Biochim Biophys Acta 1971, 240:463-47I.

44. Van Holde K: The origins of life and evolution. Edited by: Halvorson HO, van Holde KE. Alan R Liss, Inc New York; 1980:31.

45. Saladino R, Crestini C, Busiello V, Ciciriello F, Costanzo G, Di Mauro $\mathrm{E}$ : Origin of Informational Polymers. Differential stability of 3,- and 5,-phosphoester bonds in deoxy monomers and oligomers. J Biol Chem 2005, 280:35658-35669.

46. Saladino R, Crestini C, Ciciriello F, Di Mauro E, Costanzo G: Origin of Informational Polymers: Differential Stability of Phosphoester Bonds in Ribo Monomers and Oligomers. J Biol Chem 2006, 28 I :5790-5796.

47. Huminicki DMC, Hawthorne FC: The Crystal Chemistry of the Phosphate Minerals. In "Phosphates Geochemical, Geobiological, and Materials Importance" Volume 48. Edited by: Matthew L Kohn, John Rakovan, John M Hughes. The Mineralogical Society of America, Washington, DC; 2002.

48. Soukup GA, Breaker RR: Relationship between internucleotide linkage geometry and the stability of RNA. RNA 1999, 5:1308-1325.

Publish with Bio Med Central and every scientist can read your work free of charge

"BioMed Central will be the most significant development for disseminating the results of biomedical research in our lifetime. "

Sir Paul Nurse, Cancer Research UK

Your research papers will be:

- available free of charge to the entire biomedical community

- peer reviewed and published immediately upon acceptance

- cited in PubMed and archived on PubMed Central

- yours - you keep the copyright

Submit your manuscript here:

http://www.biomedcentral.com/info/publishing_adv.asp 